\title{
PONTOS NODAIS PARA A FORMAÇÃO DO PEDAGOGO*
}

\author{
Leticia Jensen de Oliveira Costa, \\ Secretaria de Educação do Estado do Paraná, Curitiba, Paraná, Brasil
}

\begin{abstract}
Resumo: Este artigo apresenta os resultados de uma pesquisa que analisou como Instituições de Ensino Superior têm elaborado os Projetos Políticos Pedagógicos (PPP's) de seus Cursos de Pedagogia a partir das proposições das DCNP/2006. Como metodologia de pesquisa foi utilizada a análise documental das DCNP/2006 e dos PPP's. A análise partiu destas duas hipóteses iniciais: nas atuais propostas de formação, há uma tendência de desintelectualização e as normatizações oficiais podem assumir uma expressão diferente da proposta por seus legisladores, amparada nos conceitos de "recontextualização", de Basil Bernstein, e de "práticas gazeteiras", de Michel de Certeau. Fez-se necessário um resgate teórico das análises realizadas por diversos autores a respeito das influências inseridas no Curso de Pedagogia pelo contexto de reformas educativas desenvolvidas na década de 1990.

Palavras-Chave: Curso de Pedagogia. DCNP/2006. Recontextualização e Reformas Educativas.
\end{abstract}

\section{INTRODUÇÃO}

Este artigo traz os resultados de uma pesquisa que buscou compreender quais implicações as Diretrizes Curriculares Nacionais para o Curso de Pedagogia (DCNP/2006) trazem para a formação do pedagogo. Para atingir o objetivo dessa pesquisa, foram analisados os Projetos Políticos Pedagógicos (PPP's) de Cursos de Pedagogia de duas Instituições de Ensino Superior (IES 1 e 2), observando como estas têm incorporado, em seus documentos, as orientações das DCNP/2006. Além disso, este texto apresenta a análise de alguns conceitos orientadores das propostas de Cursos. Fez-se necessário

\footnotetext{
* Artigo recebido em 31/10/2012 e aprovado em 15/1/2013.
} 
um resgate teórico das análises realizadas por diversos autores a respeito das influências inseridas no Curso de Pedagogia pelo contexto de reformas educativas desenvolvidas na década de 1990, bem como das diferentes concepções de formação e atuação profissional que disputaram espaço durante o processo de elaboração das DCNP/2006.

Partiu-se de duas hipóteses iniciais. A primeira delas é a de que, nas atuais propostas de formação, há uma tendência de desintelectualização. $E$ a segunda de que as normatizações oficiais podem assumir uma expressão diferente daquela proposta por seus legisladores, amparada nos conceitos de "recontextualização", de Basil Bernstein, e de "práticas gazeteiras", de Michel de Certeau.

As instituições escolhidas para a análise são públicas e federais, com contextos de criação diferentes. A IES 1 situa-se na Região Sul e o Curso de Pedagogia é ofertado desde 1938; já o Curso da IES 2 encontra-se na Região Sudeste e foi criado em 2007. A análise dos PPP's dos cursos permitiu constatar que, com relação às atuais propostas de formação do pedagogo, é possível visualizar convergências e divergências entre as concepções das duas IES, na medida em que as IES respondem de maneira diferente às normatizações oficiais. Dessa forma, percebem-se as marcas das DCNP/2006 nas propostas de formação, mas não são as mesmas, pois o currículo não é um campo neutro, passível de homogeneização, é o resultado de disputa de forças e conflito de ideias.

Neste artigo, apresenta-se a observação realizada quanto à organização curricular proposta pelas IES, pois, no decorrer deste estudo, um questionamento tornou-se recorrente: Se a formulação de um PPP é obrigatória a partir da Lei de Diretrizes e Bases da Educação (LDB 9394/96), considerado este o documento mais importante de um curso de graduação, e se há a exigência de que, para a elaboração de um PPP, este deva estar de acordo com as normatizações oficiais, como é possível que as IES formulem currículos tão diferentes? Ou dito de outra forma, a constatação de que as IES analisadas têm entendimentos diferentes em relação à formação do pedagogo e que, portanto, elaboraram propostas diferenciadas leva a uma reflexão: é possível uma instituição propor um currículo e consequentemente uma formação diferente daquilo que propõe uma diretriz?

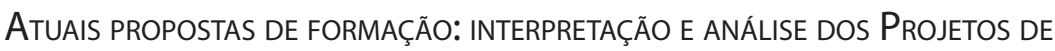 CuRsos}

A LDB 9394/96 introduziu mudanças que obrigaram as universidades a rever a forma de organizar os currículos dos cursos de graduação, em virtude 
da perda da obrigatoriedade de currículos mínimos e da rigidez curricular na estruturação dos cursos. Esse fato possibilitou a produção de propostas de formação diferenciadas.

O conceito de "recontextualização"1 construído por Bernstein (1997) possibilita a explicação de como, ao formular seus PPP's e suas Propostas Curriculares, as IES reinterpretam os documentos orientadores e normatizadores criando novos significados para eles e favorecendo trajetórias formativas diferenciadas das propostas instituídas pelo Estado regulador. Embora as normatizações oficiais tenham um aspecto regulatório, "que mantém as questões curriculares sob os auspícios do governo central", é possível perceber, no campo da prática pedagógica, "a realização de propostas de curso com caráter diferenciado ao das Diretrizes e, em alguns casos, contra-hegemônico" (SCHNEIDER, 2007, p. 166).

Em relação ao tema, Colontonio $(2010)^{2}$ traz algumas considerações que levam ao entendimento de que entre a normatização oficial, as propostas curriculares e a prática pedagógica há uma distância considerável, visto que "a Lei não possui força própria e não se cria aleatoriamente, ela é fruto de disputas e alianças formadas em redes sociais que primam pelo seu reconhecimento" (COLONTONIO, 2010, (p. 99). Os documentos oficiais não garantem que as diretrizes sejam adotadas no sentido proposto por seus legisladores, pois podem ser redefinidas. Dessa forma, as "prescrições curriculares, estruturais ou burocráticas" provocam um duplo movimento na prática "por um lado ela muda e por outro resiste. Deste duplo movimento surge um novo produto, imprevisível em relação ao que estava prescrito" (p. 99).

Schneider (2007), em sua análise, constatou que as normatizações oficiais podem "produzir práticas curriculares com diferentes percursos formativos e possibilitar, por isso, a construção de caminhos que não representem simplesmente adesão irrefletida às políticas curriculares oficiais" (p. 18). Esta autora afirma que as políticas curriculares não são práticas verticalizadas e, portanto, não cabem às IES "apenas o papel de cumprimento das determinações e dos preceitos legais" (SCHNEIDER, 2007, p. 18).

Partindo do conceito de "recontextualização", a autora considera que os PPP's são

construídos no campo institucional, e que extrapolam à pretensa homogeneidade, não como manifestações unicamente da resistência de seus idealizadores aos textos legais. Tampouco acreditamos na submissão ingênua da produção de propostas que buscam uma sintonia afinada às determinações oficiais. Dadas as possibilidades de recontextualização dos textos oficiais no contexto da prática pedagógica, o que nos parece mais coerente é que as práticas institucionalizadas são pensadas tanto nas suas especificidades 
quanto na sua unidade. Condicionadas pelos processos históricos vivenciados, elas manifestam os graus de autonomia alcançados em relação aos textos produzidos pelo poder central. (SCHNEIDER, 2007, p. 126)

Para além das prescrições das normas oficiais e dos currículos organizados pelas IES, há as práticas dos sujeitos que, de acordo com Certeau (2007, p. 97),

traçam "trajetórias indeterminadas" aparentemente desprovidas de sentido porque não são coerentes com o espaço construído, escrito e pré-fabricado onde se movimentam. São frases imprevisíveis num lugar ordenado pelas técnicas organizadoras de sistemas [...] embora fiquem enquadradas por sintaxes prescritas (modos temporais dos horários, organizações paradigmáticas dos lugares etc.), essas "trilhas" continuam heterogêneas aos sistemas onde se infiltram e onde esboçam as astúcias de interesses e de desejos diferentes. Elas circulam, vão e vêm, saem da linha e derivam num relevo imposto, ondulações espumantes de um mar que se insinua entre os rochedos e os dédalos de uma ordem estabelecida. (Grifos do original)

Tomando como pressuposto as afirmações de Certeau (2007) e de Bernstein (1997), partiu-se para a análise dos PPP's, buscando evidenciar as "ressignificações" das normas oficiais e as "práticas gazeteiras" perpetradas pelas IES. Assim, a análise considerou os pontos de encontro e de desencontro dos documentos institucionais. Com a análise dos PPP's, foi possível verificar que, na IES 2, revela-se a preocupação de evidenciar a sintonia com os princípios orientadores das DCNP/2006. Já na IES 1, ocorre o oposto, a proposta produzida retrata a tentativa de demonstrar sua posição contrária a certos aspectos das DCNP/2006.

Na Proposta Curricular do Curso da IES 1, não há dissociabilidade hierárquica entre a docência, a organização do trabalho pedagógico e a pesquisa, pressuposto que descende do princípio do "pedagogo unitário". Já na Proposta Curricular do Curso da IES 2, há a definição deste como um curso de formação de docentes; em razão da relevância desta IES na formação de profissionais da saúde, há na sua proposta de formação pedagógica interface com a proposta de formação médica (Residência Pedagógica).

Em ambas as propostas, foi constatado o comprometimento das IES em adequar a carga horária de seus cursos às determinações das DCNP/2006. A IES 1 optou pela carga mínima de duração do curso, proposto pela norma oficial, ou seja, 3.200 horas distribuídas da seguinte forma: i) 2.800 horas dedicadas às atividades formativas, inclusas às 100 horas para a realização de Trabalho de Conclusão de Curso (TCC); ii) 300 horas dedicadas ao Estágio Supervisionado; e iii) 100 horas de atividades formativas. Já a IES 2 optou por 
3525 horas dispostas da seguinte forma: i) Unidades Curriculares Obrigatórias Fixas de Domínio Conexo - 240 horas; ii) Unidades Curriculares Obrigatórias Fixas de Área - 2.460 horas; iii) Unidades Curriculares Obrigatórias Eletivas de Área - 225 horas; iv) Unidades Curriculares Obrigatórias Eletivas de Domínio Conexo - 120 horas; v) Estágio Curricular, disposto na forma de Residência Pedagógica - 300 horas; vi) Trabalho de Conclusão de Curso (Monografia) - 75 horas; e vii) Atividades Complementares/Acadêmico-culturais - 105 horas.

Um aspecto em que predominou a similaridade quanto às proposições das IES foi a preocupação em instituir a pesquisa, como princípio educativo, introduzindo em suas Propostas Curriculares a realização de TCC. No entanto, a diferença se apresenta no entendimento da função da pesquisa na formação do futuro pedagogo. Na proposta da IES 2, há a vinculação da pesquisa com a aquisição de competências e habilidades de investigação para a solução de problemas do cotidiano, enquanto a IES 1 propõe a pesquisa como instância formadora do pedagogo como intelectual, capaz de produzir conhecimento, se posicionando sobre uma problemática educacional. Ambas as IES consideram a necessidade de divulgar as produções de seus alunos na forma de seminários, textos, pôsteres, entre outras.

Percebe-se também, como convergência entre as Propostas Curriculares, a preocupação com a escola pública, buscando a superação da desqualificação profissional que sempre esteve presente na educação formal brasileira.

A abordagem que as IES apresentam da relação teoria/prática na formação do pedagogo descende do seu tipo de afinidade com as DCNP/2006; dessa forma, observam-se entendimentos diferenciados a respeito dessa questão. No PPP da IES 2, que apresenta uma similaridade maior com as proposições da DCNP/2006, a prática profissional foi tomada como eixo norteador das ações pedagógicas, privilegiando como estratégia metodológica a resolução de situações-problema. Já a IES 1, que apresenta crítica ao modelo de formação proposto pelas DCNP/2006, parte do princípio de que a teoria é que deve fundamentar as ações pedagógicas, incluindo a prática profissional. Entretanto, percebe-se, nas duas IES, a preocupação em articular as categorias teoria e prática, tomando o cuidado de não separá-las como momentos afastados e distintos.

Os estudos teóricos permitem compreender que as mudanças curriculares (micro) operadas nos Cursos de Pedagogia se articulam a um movimento histórico (macro), de desintelectualização e fragilização na formação e também com as políticas educacionais de formação em nível superior. 


\section{Princípios norteadores das Propostas de CuRsos: tendênCia de "DESINTELECTUALIZAÇÃo"}

A análise proposta de examinar os documentos oficiais (DCNP/2006) e os currículos dos cursos de pedagogia tem o objetivo de demonstrar empiricamente como os conceitos instaurados pelas políticas de formação da década de 1990 têm sido assumidos ou questionados pelas propostas de formação do pedagogo. Assume-se a década de 1990 como marco de referência para a análise pretendida, pois diversos autores apontam que, nessa década, proliferaram teorias e documentos oficiais que serviram de base para as reformas educacionais (MORAES, 2003; MASSON, 2009; SHIROMA, 2003).

Shiroma (2003) afirma que a reforma educacional da década de 1990 teve como meta operar a "desintelectualização" do professor. Esta é uma tendência também apontada por Moraes (2003), como o resultado de uma série de ocorrências, dentre elas as recomendações de organismos multilaterais ligados de alguma forma à educação (Banco Mundial, Unesco, UNICEF); a conciliação dessas recomendações ao objetivo governamental em reduzir gastos com a educação e a demanda mercadológica por um profissional de "novo tipo" são características necessárias à produção flexível.

Moraes (2003) delineia que as reformas educacionais empreendidas a partir da década de 1990, na qual se inserem as DCNP/2006, foram corroboradas por uma teoria produzida com o objetivo de dar legitimidade às proposições oficiais. Essa produção teórica introduziu uma gama de conceitos aliados aos objetivos reformistas; dessa forma, conceitos como "desenvolvimento de competências e habilidades", "sociedade do conhecimento", "aprender a aprender" e "educação ao longo da vida" tornaram-se comuns, criando um clima de consenso na sociedade, assumidos como objetivos a ser alcançados.

Embora, em seu texto, Moraes (2003) trate especificamente da formação docente, ela apresenta algumas questões consideradas importantes para as discussões que se propõe. De acordo com a autora, a fragilização ou a "desintelectualização" na formação remete ao conhecimento e à atitude humana perante o conhecimento. Na sociedade atual, a relação do homem com o conhecimento tornou-se definidora da capacidade de competitividade e desenvolvimento econômico, o que fez surgir a demanda por um novo projeto educativo, justificado pelos cenários construídos como o de "sociedade do conhecimento e da informação", ou ainda de "sociedade aprendente ou do aprendizado" (MORAES, 2003).

A autora afirma que as políticas educacionais de formação têm concorrido para uma "desintelectualização", um empobrecimento do ato de conhecer, um recuo da teoria e a tomada do sentido pragmático do 
conhecimento, enfatizando o utilitarismo produzido por este. As atuais políticas de formação estariam fundamentadas no conceito de "prática reflexiva", com uma excessiva ênfase na prática e uma reflexão pautada no saber de experiência, formação esta restritiva das possibilidades críticas da produção do conhecimento, pelo fato de pautar a reflexão na ação, na execução de uma tarefa, sem reconhecer a necessidade de reflexão prévia. A problemática dessa tendência está na sua articulação com a noção de competência profissional, e na criação de um consenso que culpabiliza o sujeito pelo seu fracasso social, por não possuir as competências e habilidades exigidas pelo mercado de trabalho.

Moraes (2003) também questiona a proposição da sociedade contemporânea vista como a sociedade do conhecimento e a adoção do conhecimento articulado organicamente à produção, associando essas proposições aos objetivos Iluministas. ${ }^{3}$ No entanto, define que o paradigma instaurado na atualidade trata-se de um "Iluminismo às avessas", pois enquanto os ideais Iluministas pretendiam que, por meio da educação, o homem conquistasse a liberdade e a igualdade, e entendia que somente pelo esclarecimento dos indivíduos seria possível atingir tal fim, considerando que o homem poderia se emancipar por meio da razão e do saber, ao qual todos deveriam ter livre acesso (COSTA, 2010).

De acordo com Moraes (2003), o lluminismo às avessas

também percebe no conhecimento virtudes 'intrinsecamente democráticas' sobretudo a de que é infinitamente ampliável. Tal característica, a de poder dilatar cada vez mais seu horizonte, faz do conhecimento um bem, um recurso e um serviço que não desgasta e, portanto, concede-lhe lugar importante como aporte à produção. No entanto, a inversão procedida fez perder-se no caminho o componente teórico-crítico essencial, a racionalidade capaz de reflexionar sobre si mesma e sobre a natureza de seu objeto, privando-se, assim, do incondicional impulso emancipatório que está na raiz da vocação filosófica. Em seu lugar instaura-se, por um lado, o conhecimento instrumental ou técnico-operatório; por outro, a associação vulgar das empirias, um 'saber-fazer' conformado à aceitação do status quo. (P. 18; grifos do original)

\section{O CONHECIMENTO NAS PROPOSTAS DE FORMAÇÃO DO PEDAGOGO}

A concepção de conhecimento presente nos documentos oficiais e a forma como ela aparece nas propostas curriculares são um indicativo da fundamentação da formação proposta pelas IES. Com relação a esse conceito, as IES analisadas têm abordagens diferenciadas, fato que fica demarcado, pelo 
menos em suas propostas pedagógicas. Como as propostas pedagógicas são influenciadas em sua elaboração pelas DCNP/2006 que dão regulamentação ao Curso, convêm analisar como o conceito "conhecimento" é abordado nesse documento.

As DCNP/2006 afirmam que a docência é a base para a formação do pedagogo, portanto, define que os conhecimentos a serem trabalhados durante a formação devem privilegiar esse âmbito da atuação profissional. Contudo, ao referir-se ao conhecimento, a Resolução no Art. $3^{\circ}$ prevê que o Curso de Pedagogia deva propiciar contato com informações e o desenvolvimento de habilidades, desconfigurando o sentido epistemológico do termo, atribuindo a ele um sentido mais articulado com o conceito de qualificação e com o desenvolvimento de competências exigidas pelo mercado.

Art. $3^{\circ} \mathrm{O}$ estudante de Pedagogia trabalhará com um repertório de informações e habilidades composto por pluralidade de conhecimentos teóricos e práticos, cuja consolidação será proporcionada no exercício da profissão, fundamentando-se em princípios de interdisciplinaridade, contextualização, democratização, pertinência e relevância social, ética e sensibilidade afetiva e estética. (BRASIL, 2006)

Nesse mesmo artigo pode-se perceber uma indicação reveladora da concepção que norteia a proposta, na medida em que se protela a consolidação da formação para o exercício da profissão. Seria uma vinculação com o fenômeno observado por Shiroma (2003), de que nas atuais políticas de formação, a fragilização na formação pode ser compensada pelo treinamento em serviço?

A proposta pedagógica formulada pela IES 1 propõe uma formação que vá além daquela precarizada pela ênfase na prática ou em apenas uma das possibilidades de atuação do pedagogo; essa proposta reafirma o papel dele como intelectual, manifestando a necessidade de que a formação deve abranger o domínio dos pressupostos científicos da educação e a compreensão do processo pedagógico em sua totalidade e complexidade.

A IES 2 propõe uma formação com clara vinculação às proposições das DCNP/2006, destacando a compreensão de que o desenvolvimento de competências e habilidades constitui-se em um pressuposto de formação. Há ainda, na IES 2, uma preocupação em inserir o futuro pedagogo em situações de contato com a prática profissional desde o início do curso, o que fundamenta a formação em uma variada vivência do exercício profissional. Seria esse entendimento tomado pela IES 2 resultado da necessidade em articular suas proposições àquelas propostas pelas DCNP/2006, tendo em vista que o curso de pedagogia é novo e precisaria de aprovação dos órgãos competentes para a sua implantação? 
A pesquisa acadêmica configura-se como produtora do conhecimento; assim, convém apresentar o entendimento das IES com relação à pesquisa, trazendo excertos dos projetos para visualizar como é tratada essa problemática. Em ambas as IES, a pesquisa é entendida como instância formadora associada à produção do conhecimento. No entanto, na IES 1, observa-se a preocupação em compreender a realidade do fenômeno educativo imprimindo ao curso a dimensão da produção e divulgação do conhecimento:

Retomando a questão fundante da formação do pedagogo, referente à natureza do trabalho pedagógico, pode-se afirmar que o ensino e a formação não podem prescindir do trabalho intelectual, próprio da função pedagógica. Ao se voltarem para essa questão, as disciplinas do curso de Pedagogia têm na pesquisa todos os elementos para a reflexão intelectual, que não prescinde da prática. (PPP IES 1, 2007, p. 37)

Nesse mesmo sentido, a IES 1 mostra a importância de os professores reconhecerem a necessidade da adoção de práticas de ensino por meio da pesquisa:

Importa que os professores do curso de Pedagogia em seu conjunto considerem os objetos de suas disciplinas aplicados à compreensão do fenômeno educativo, imprimindo ao curso a perspectiva da pesquisa, da produção e divulgação de conhecimento. (PPP IES 1, 2007, p. 45)

Na IES 2, embora também haja orientações a respeito da produção e difusão do conhecimento científico e tecnológico do campo educacional, há uma ênfase na dimensão propositiva da pesquisa, e no conceito expresso nas DCNP/2006, do professor reflexivo.

A pesquisa, compreendida como processo formador, está aqui presente tanto nas disciplinas específicas que visam oferecer as ferramentas básicas de procedimentos científicos na construção de conhecimentos, quanto na concepção do professor e do gestor como um pesquisador da prática - traduzida numa atitude de permanente questionamento diante dos problemas que envolvem o ato educativo e a prática docente. (PPP IES 2, 2010, p. 37)

Em relação aos aspectos metodológicos, no Curso da IES 2, verificouse que a resolução de situações-problema configura-se como uma estratégia didática adotada. Aliada a esta, destaca-se também que, nas propostas de ambas as IES, existe a indicação da necessidade de propor projetos de intervenção para os campos de estágios. 
Moraes (2003) produz argumentos que concorrem para o entendimento da forma que o conhecimento tem assumido e a vincula às transformações socioeconômicas do último século, destacando que estas provocaram efeitos sobre as práticas sociais e sobre a educação. A autora afirma que "o elevado grau de competitividade ampliou a demanda por conhecimentos e informações e, consequentemente, a educação foi eleita como barreira estratégica para fazer face à velocidade das mudanças" (p. 152).

Esse novo projeto educativo busca não mais a transmissão dos conteúdos tradicionais e sim o desenvolvimento das competências, segundo os princípios da Comissão internacional sobre Educação para o Século XXI da Unesco, que apresentam um discurso denominado por Moraes (2003) como "celebração do fim da teoria":

Não há o que justifique memorizar conhecimentos que estão sendo superados, ou cujo acesso é facilitado pela moderna tecnologia. O que se deseja é que os estudantes desenvolvam competências básicas que lhes permitam desenvolver a capacidade de continuar aprendendo. (Unesco, 2003, p. 27)

Para entender as bases desse processo que Moraes (2003) aponta como um retrocesso da teoria, faz-se necessário refletir sobre os indícios dessa degradação teórica no campo educacional.

Em linhas gerais, pode-se afirmar que no plano teorético as propostas que desqualificam a teoria têm origem na convicção da falência de uma determinada concepção de razão: a chamada razão moderna de corte iluminista, emblemática das culturas liberais do ocidente, produto de uma burguesia ainda em luta por sua definição e consolidação em face de seu 'outro', feudal, aristocrático. (p. 155)

As atuais políticas de formação e as propostas curriculares derivadas dessas políticas trazem, em seus textos, a marca da "crise da modernidade", articuladas a um conjunto de mudanças integradas, que refletem na adoção das concepções das teorias pós-modernas e que, dentre outras coisas, afirmam a desconstrução dos conhecimentos históricos, "a ideologia predominante, destacada em todos os manuais educacionais, é a de que a 'flexibilidade' e a 'inovação' permanente dos currículos e das práticas pedagógicas torna-se a única cura para uma insegurança já insustentável" (SILVA, 2010, p. 172).

CONCEITOS CONSTRUÍDOS: APRENDIZAGEM AO LONGO DA VIDA, PROFESSOR REFLEXIVO E DESENVOLVIMENTO DE COMPETÊNCIAS E HABILIDADES

Conforme apresentado, para corroborar teoricamente as políticas educacionais instauradas pela década de 1990, são formulados conceitos. 
Dentre os conceitos repetidos à exaustão até que se tornassem naturais, podem ser apontados: o de "educação ou aprendizagem ao longo da vida", o de "formação do professor reflexivo" e o de "desenvolvimento de competências e habilidades"; constituindo-se esta em uma nova ordem educativa, houve uma "multiplicação de iniciativas internacionais relacionadas com o tema" (ALHEIT; DAUSIEN, 2006, p. 181).

Autores como Alheit e Dausien (2006) configuraram-se como intelectuais orgânicos em defesa da teoria da aprendizagem ao longo da vida. Eles afirmam que a aprendizagem, ao longo da vida, deve constituir o princípio orientador das ofertas de educação e formação, e deve ser baseada em uma grande variedade de contextos de aprendizagens. O conhecimento e a relação dos sujeitos com o conhecimento aparecem como questão central. Os autores também assinalam que as transformações sofridas, do ponto de vista econômico e social, provocam mudanças no ato educativo, "aprender ganha um significado novo para a sociedade inteira, para as instituições educativas e para os indivíduos" (p. 178).

O conceito de "educação ao longo da vida" assume a função de possibilitar aos indivíduos, do ponto de vista econômico, a competitividade, de assegurar a empregabilidade e a capacidade de adaptação às mudanças no mundo do trabalho. No entanto, Silva (2010, p. 168) mostra as consequências dessa nova ordem educativa:

A educação, agora, consiste numa responsabilidade do trabalhador, que deve, diante de um cenário de incerteza e efemeridade (marcas de uma sociedade altamente competitiva e volátil), "formar-se" continuamente para poder "adaptar-se" ao ritmo "eterno" das mudanças. Em suma, no neoliberalismo, na fase flexível do capital (modernidade flexível), a educação passa de "direito" do cidadão a "dever" do consumidor.

Esse conceito - "educação ao longo da vida" - está articulado a um contexto em que as mudanças sociais e econômicas operadas na atualidade exigem dos sujeitos competências e habilidades, dentre elas a flexibilidade, para adaptar-se a essas mudanças. Dessa forma, propõem-se transformações nos projetos de formação, aduzindo que "os limites dos programas de formação devem ser transformados, novas redes sociais e novos ambientes de formação devem ser criados" (ALHEIT; DAUSIEN, 2006, p. 180).

A importância do conhecimento científico é substituída pelos saberes docentes. Dessa forma, a base das reformas educativas tem sido "encontrar, nos cursos de formação de professores, uma nova articulação e um novo equilíbrio entre os conhecimentos produzidos pelas universidades a respeito do ensino e os saberes desenvolvidos em suas práticas cotidianas" (TARDIF, 
2002, p. 23). Essas reformas baseiam-se na ideia de que os conhecimentos científicos são produzidos e ficam enclausurados na academia sem nenhuma conexão com a atividade profissional. Porém, enquanto o conhecimento científico é produzido a partir da atuação dos homens sobre a natureza, por meio do trabalho, os saberes docentes articulam-se com o ensino por meio da prática profissional. Segundo essa teoria, o conhecimento assume uma nova função, não se constitui mais como capital cultural, que deve ser reproduzido e assegurado em sua perenidade. Para Alheit e Dausien (2006), as novidades tecnológicas e organizacionais que têm penetrado, ampliado e transformado os processos de produção industrial dependem mais das habilidades individuais do que dos conhecimentos historicamente construídos, demandando novas formas de saberes.

A finalidade da formação e da aprendizagem transformou-se espetacularmente. Ela não consiste mais em pôr à disposição nem em transmitir saberes, valores ou competências preestabelecidos, porém em permitir, de algum modo, a 'osmose dos saberes', sob a forma de trocas permanentes da produção individual e da gestão organizada do saber. (ALHEIT; DAUSIEN, 2006, p. 182; grifos do original)

Trata-se, assim, de um processo de "responsabilização" dos indivíduos pelo seu processo de formação, o que demanda uma mudança de paradigma na organização desse processo.

A questão central da pedagogia não é mais saber como uma determinada matéria pode ser ensinada da maneira mais eficaz possível, porém quais são os ambientes de aprendizagem que são os melhores para estimular a responsabilização dos processos de aprendizagem pelos próprios aprendentes, ou seja, como o aprender pode ser "aprendido". (ALHEIT; DAUSIEN, 2006, p. 183; grifos do original)

Embora possa parecer que o conceito de conhecimento e o de saberes propõe uma mesma formação fundamentada no trabalho, a incoerência desse ideal de formação está no não reconhecimento das contradições existentes na sociedade de classes, e no entendimento de que todos os indivíduos têm acesso ao mesmo nível de educação. Concebida dessa maneira, a educação apenas reproduz os elementos deformadores da lógica do capital.

Os próprios autores indicam o peso desse processo de exclusão sobre os indivíduos:

As esperanças da"sociedade do saber" exercem uma pressão mais forte sobre os indivíduos, a quem se pedem que apresentem padrões determinados de saber e de qualificação. Para aqueles que não se enquadram nas exigências, as 
consequências são mais graves do que na sociedade industrial convencional. (ALHEIT; DAUSIEN, 2006, p. 185)

Moraes (2003) afirma que o conceito de "aprendizagem ao longo da vida" se articula a um mercado cada vez mais insaciável, e que os países vêm sofrendo pressões para adequar seus sistemas educativos a uma economia sofisticada e seletiva, gerando "cidadãos capazes de manipular ou operar as tecnologias de informação e comunicação, e dispostos a se atualizar ao longo da vida" (p. 152). A autora afirma também que a educação pautada nesse ideal de efetivar a aprendizagem ao longo da vida mascara as contradições, pois assenta-se no ideal de possibilitar a empregabilidade e a competitividade no mercado de trabalho.

No mesmo sentido, encontra-se a contribuição de Silva (2011), visto que a autora também analisa as consequências desse conceito para a educação e afirma que "busca-se, portanto, uma nova escola, a educação para todos, a educação ao longo da vida, a educação que promova a qualificação para o mercado de trabalho" (p. 165).

Além disso, a autora afirma que, com essa concepção,

houve um alargamento da concepção de educação, abandonando a ideia de educação centrada no ensino de conteúdos para aquela centrada na aprendizagem do indivíduo, enaltecendo os processos educativos não escolares e a continuidade, ao longo da vida, em adquirir informações, atualizando suas habilidades e competências bem como seus valores. (SILVA, 2011, p. 166; grifos do original)

Outro conceito que também se relaciona com a forma que o conhecimento assume na atualidade é o de "professor reflexivo". Os autores que referenciam este conceito são Schön (2000), Tardif (2002), Zeichner (1993) e Perrenoud (1993). Marques (2008), em seu texto, analisou a produção do conhecimento sobre a formação de professores e percebeu que atualmente existe uma orientação da organização curricular para a formação inicial: estes profissionais devem privilegiar uma aprendizagem prática da reflexão, em oposição ao conhecimento científico elaborado e sistematizado a partir das pesquisas.

Já Kuenzer e Rodrigues (2006) afirmam que, nessa nova epistemologia, o conhecimento é construído a partir da reflexão dos profissionais sobre as suas práticas; dessa forma, devem "pensar o que fazem, enquanto fazem" (p. 199). Essa análise remete à noção de conhecimento presente nas propostas de formação, de forma que a proposta de formação de um profissional reflexivo "deverá ser orientada pela competência de cada um em construir saberes e utilizá-los com iniciativa e criatividade na resolução de problemas práticos" (MARQUES, 2008, p. 36-37). 
Percebe-se que estas questões estão presentes nas formulações curriculares das IES analisadas, mas elas são articuladas de forma diferenciada. Enquanto a IES 1 reconhece as diferentes concepções de formação, e parte suas proposições da identificação, problematização e ampliação do conceito de conhecimento, com posicionamentos críticos às referências pós-modernas que minimizam a importância do conhecimento científico, a IES 2 opta por uma proposta de formação que assume a prática como base para o desenvolvimento dos estudos pedagógicos, atendendo a uma concepção que, de acordo com Kuenzer e Rodrigues (2006), "privilegia a prática em detrimento da teoria", surgindo uma nova epistemologia denominada por esta autora de "epistemologia da prática" (p. 198).

Essa concepção "ao invés de articular teoria e prática, acentua a desarticulação, à medida que condiciona os estudos teóricos mais avançados à prática" (KUENZER; RODRIGUES, 2006, p. 198; grifos do original). Ainda segundo as autoras, essa epistemologia para a formação assenta-se na compreensão de que o conhecimento produzido na academia é insuficiente para corroborar a prática docente, pois os professores não compreendem o conhecimento produzido na academia.

O conceito de professor reflexivo se faz presente no currículo da IES 2, quando da tomada da prática como elemento norteador, enfatizando a construção do conhecimento a partir do questionamento, da identificação, teorização e investigação dos problemas emergentes no cotidiano da formação; embora haja menção à integração teoria e prática, o que sobressai é a dimensão instrumental da teoria.

A noção de competência também aparece nas propostas curriculares de ambas as IES. Contudo, enquanto a IES 1 apresenta a necessidade de haver um posicionamento crítico quanto à desqualificação do conhecimento científico introduzido pela noção de competências, a IES 2 alia-se ao pressuposto de inovação introduzido por esse conceito e propõe uma organização curricular que valoriza a variação de tempos e espaços escolares.

\section{CONSIDERAÇÕES FINAIS}

Ao analisar os PPP's dos Cursos de Pedagogia das IES escolhidas, foi possível perceber convergências e divergências entre as propostas das IES e entre estas e as normatizações oficiais. Essa constatação permite observar que, embora o Estado tenha uma função reguladora, produzindo legislações com o objetivo de normatizar os cursos ofertados pelas IES, as DCNP/2006 tomam um sentido diferente ou não daquele proposto por seus legisladores. 
De acordo com o conceito de "recontextualização", de Bernstein (1997), os textos oficiais, ao serem retirados de seus contextos iniciais de elaboração e relocados em outro contexto, podem ser reconfigurados de acordo com os contextos em que foram inseridos. Para Certeau (2007), buscando viver do melhor modo possível a ordem social, o homem "inventa o cotidiano" por meio das "artes de fazer", "táticas de resistência", "práticas gazeteiras", alterando "os objetos e códigos, se reapropria do espaço e o usa a seu jeito".

Na apresentação dos PPP's dos cursos das duas IES escolhidas para a análise, foi possível encontrar elementos/indícios que demonstram "práticas gazeteiras" ou agentes de "recontextualização". No entanto, essas práticas também não são isoladas e se relacionam com a concepção de profissional que cada IES deseja formar. Dessa forma, foi possível observar atitudes que representam adesão às propostas oficiais e outras que representam resistência.

Ao mesmo tempo, observou-se, nas produções teóricas sobre o tema, que desde a década de 1990 as reformas educativas foram amparadas por uma gama de conceitos de racionalidade instrumental, que têm uma influência no entendimento do conhecimento e consequentemente para a formação. Sob essa perspectiva, foram analisados os conceitos de aprendizagem ao longo da vida, professor reflexivo e de ensino baseado no desenvolvimento de competências e habilidades, buscando explicar a sua influência para o campo da formação. Constatou-se, com essas análises, que o conhecimento tem assumido um aspecto secundarizado, articulado tão somente ao setor produtivo, o que traz prejuízos para a formação humana em sentido integral.

As análises desenvolvidas relacionadas ao objetivo de buscar entender como as concepções sobre docência e formação estão articuladas a um contexto de reformas políticas, corroboradas por uma nova forma de pensar o homem, a ciência e a cultura, possibilitaram compreender que as normatizações oficiais, a produção teórica sobre educação e a organização curricular estão ligadas a um contexto de mudanças, a saber: o surgimento das novas tecnologias de informação e transformações no conceito de ciência, e que estas produzem implicações para as práticas culturais e sociais; no entanto, todo esse contexto está articulado aos arranjos da economia capitalista e ao acúmulo de capital. A educação, nessa perspectiva, assume a função específica de formação do trabalhador, com capacidade e habilidades técnicas, manuais, cognitivas, intelectuais, adaptado para a flexibilidade e para a resolução de problemas. Forja-se, para esse contexto, uma produção teórica que dê legitimidade às normatizações oficiais e orientem as práticas educacionais desenvolvidas no país. 
Existem vários conceitos que orientam a formação e atuação profissional docente na atualidade como, por exemplo, "aprendizagem ao longo da vida, professor reflexivo e desenvolvimento de competências e habilidades". A estes conceitos somam-se outros tantos que apresentam a mesma tendência e corroboram o empobrecimento da noção de conhecimento, a valorização da epistemologia da prática e o desenvolvimento de competências e habilidades específicas, o que torna secundária a importância da aquisição de uma sólida fundamentação teórica e colabora para a formação de um profissional desintelectualizado.

\section{NODAL POINTS FOR THE FORMATION OF PEDAGOGUES}

ABSTRACT: This article presents the results of a survey which examined how Institutes of Higher Education have designed the Pedagogical Political Projects (PPPs) of their Pedagogy courses with the 2006 DCNP (National Curriculum Pedagogy Guidelines) proposals as a basis. As research methodology, a documental analysis of the DCNP/2006 and PPPs was used. The analysis was based on two initial hypotheses, namely: in current formation proposals there is a tendency towards disintellectualization and official norms can be expressed differently from that proposed by the legislators, based on Basil Bernstein's concepts of "recontextualization" and Michel de Certeau's "practices". There is a need for a theoretical salvaging of the analyses undertaken by various authors in relation to the influences on the Pedagogy course exerted by the context of educational reforms undertaken in the 1990s.

KEY wORDS: Pedagogy course. DCNP/2006. Recontextualization and Educational Reforms.

\section{PUNTOS NODALES PARA LA FORMACIÓN DEL PEDAGOGO}

REsUMEN: Este artículo expone los resultados de una investigación que analizó como la Instituciones de Enseñanza Superior han construido los Proyectos Políticos Pedagógicos (PPPs) de sus Cursos de Pedagogía a partir de las proposiciones de las DCNP/2006. Se utilizó como metodología de investigación el análisis documental, de las DCNP/2006 y de los PPP's. El análisis partió de dos hipótesis iniciales, a saber: la tendencia que hay en las actuales propuestas de formación a la desintelectualización; y las normatizaciones oficiales que pueden asumir una expresión diferente de la propuesta por sus legisladores, amparada por los conceptos de "recontextualización" de Basil Bernstein y de "prácticas gazeteiras" de Michel de Certeau. Se hace necesario un rescate teórico de los análisis realizados por diversos autores con respecto a las influencias incluidas en el Curso de Pedagogía por el contexto de las reformas educativas desarrolladas en la década de 1990. 
Palabras Claves: Curso de Pedagogía. DCNP/2006. Recontextualización y Reformas Educativas.

\section{NOTAS}

1. O conceito de recontextualização, para Basil Bernstein (1997), abrange o processo em que textos, de ordem oficial ou de produção teórica, são realocados do campo da produção do discurso (primário) para o campo da reprodução do discurso (secundário); assim, "neste processo de deslocação e relocação, o discurso original é submetido a uma transformação que o modifica a partir de uma prática concreta" (p. 189). O autor também afirma que, "quando os agentes recontextualizadores que operam em determinadas posições desse campo se apropriam de um texto, este pode sofrer uma transformação antecedente a sua relocação. A forma desta transformação é regulada por um princípio de descontextualização. Este processo se refere à mudança no texto quando se desloca para depois relocá-lo. Esse processo assegura que o texto deixará de ser o que foi" (p. 197).

2. Embora essa autora, em seu estudo, tenha privilegiado os cursos do PROEJA, sua análise sobre as reformas operadas na educação contribui para que seja entendida a forma que os documentos oficiais assumem nas IES.

3. Um dos ideais do lluminismo era o de que, por meio da razão, o homem se libertasse da autoridade da Igreja, do peso do Absolutismo e de outras autoridades ditadas pelos mitos. Esse ideal teve início no século XVIII, período que ficou conhecido como Século das Luzes ou Iluminismo (COSTA, 2010).

\section{REFERÊNCIAS}

ALHEIT, P.; DAUSIEN, B. Processo de formação e aprendizagens ao longo da vida. Educação e Pesquisa, São Paulo, v. 32, n. 1, p. 177-197, jan./abr. 2006.

BERNSTEIN, B. La estructura del discurso pedagógico: clases, códigos y control. Madrid: Ediciones Morata, 1997.

BRASIL. Conselho Nacional de Educação. Resolução n. 1/2006. Diretrizes Curriculares da Pedagogia. Diário Oficial da União, Brasília-DF, n. 92, seção 1, p. 11-12, 16 maio 2006. BRASIL. MINISTÉRIO DA EDUCAÇÃO E DO DESPORTO - MEC, Lei de Diretrizes e Bases da Educação. Diário Oficial da União, Brasília-DF. 23 de dezembro de 1996.

CERTEAU, M. de. A invenção do cotidiano: 1. Artes de Fazer. 13. ed. Tradução de Ephraim Ferreira Alves. Petrópolis-RJ: Vozes, 2007.

COLONTONIO, E. M. O currículo integrado do PROEJA: trabalho, cultura, ciência e tecnologia em tempos de semiformação. Dissertação (Mestrado em Educação) - UFPR, Curitiba, 2010. 
COSTA, L. J. O. A teoria crítica da sociedade e conceito de autonomia intelectual no campo da educação. Monografia (Especialização em Filosofia da Educação) - UFPR, Curitiba, 2010.

KUENZER, A. Z.; RODRIGUES, M. de F. As diretrizes curriculares para o curso de pedagogia: uma expressão da epistemologia da prática. In: SILVA, A. M. M. et al. (Orgs.). Novas subjetividades, currículo, docência e questões pedagógicas na perspectiva da inclusão social. XIII Encontro Nacional de Didática e Prática de Ensino. Recife: ENDIPE, 2006. p. 185-212.

MARQUES, H. J. Reflexão ou inflexão? A produção de conhecimentos sobre a formação de professores no Brasil. Dissertação (Mestrado em Educação) - UFPR, Curitiba, 2008.

MASSON, G. Políticas de formação de professores: as influências do neopragmatismo da agenda pós-moderna. 245 f. Tese (Doutorado em Educação) - Centro de Ciências da Educação, Universidade Federal de Santa Catarina, Florianópolis, 2009.

MORAES, M. C. M. de. Iluminismo às avessas: produção de conhecimento e políticas de formação docente. Rio de Janeiro: DP\&A, 2003.

PEDAGOGIA. Proposta de Reformulação Curricular para o Curso de Pedagogia. Curitiba: UFPR, 2007.

. Projeto Pedagógico do Curso de Pedagogia. São Paulo: UNIFESP, 2010.

PERRENOUD, P. Práticas Pedagógicas, Profissão Docente e Formação: perspectivas sociológicas. Publicações Dom Quixote, Instituto de Inovação Educacional, Lisboa, 1993.

SCHENEIDER, M. P. Diretrizes Curriculares Nacionais para a formação de professores da educação básica: das determinações legais às práticas institucionalizadas. Tese (Doutorado em Educação) - UFSC, Florianópolis, 2007.

SCHÖN, D. Educando o profissional reflexivo: um novo design para o ensino e aprendizagem. Porto Alegre: Artmed, 2000.

SILVA, G. L. R. da. Educação de jovens e adultos e psicologia histórico-cultural: a centralidade do trabalho na aprendizagem e no desenvolvimento de trabalhadores precariamente escolarizados. Tese (Doutorado em Educação) - UFPR, Curitiba, 2011.

SILVA, S. P. da. Modernidade/Pós-modernidade e educação no contexto do capitalismo tardio. Tese (Doutorado em Educação) - UFPR, Curitiba, 2010.

SHIROMA, E. O. O eufemismo da profissionalização. In: MORAES, M. C. M. de. Iluminismo às avessas: produção de conhecimento e políticas de formação docente. Rio de Janeiro: DP\&A, 2003. p. 61-79.

TARDIF, M. Saberes docentes e formação profissional. Petrópolis-RJ: Vozes, 2002.

UNESCO. Os quatro pilares da educação. In: Educação: um tesouro a descobrir: Relatório Jacques Delors. 8. ed. São Paulo: Cortez; Brasília-DF: MEC/Unesco, 2003.

ZEICHNER, K. M. A formação reflexiva de professores: ideias e práticas. Lisboa: EDUCA, 1993. 
Leticia Jensen de Oliveira Costa é graduada em Pedagogia, especialista em Filosofia da Educação e mestre em Educação, na linha de Mudanças no Mundo do Trabalho, todos os cursos pela Universidade Federal do Paraná. Atualmente é pedagoga - Secretaria de Estado da Educação. Tem experiência na área de Educação, atuando diretamente em atividades de apoio à equipe pedagógica e docente.

E-mail: leticiajoc@hotmail.com 